\title{
Tolerance to coxibs in patients with intolerance to non-steroidal anti-inflammatory drugs (NSAIDs): a systematic structured review of the literature
}

\author{
Tobias Bernd Weberschock • Sylke-Monina Müller • \\ Sandra Boehncke $\cdot$ Wolf-Henning Boehncke
}

Received: 28 February 2007 / Accepted: 7 April 2007 / Published online: 11 May 2007

(C) Springer-Verlag 2007

\begin{abstract}
Adverse events triggered by non-steroidal antiinflammatory drugs (NSAIDs) are among the most common drug-related intolerance reactions in medicine; they are possibly related to inhibition of cyclooxygenase- 1 . Coxibs, preferentially inhibiting cyclooxygenase-2, may therefore represent safe alternatives in patients with NSAID intolerance. We reviewed the literature in a systematic and structured manner to identify and evaluate studies on the tolerance of coxibs in patients with NSAID intolerance. We searched MEDLINE (1966-2006), the COCHRANE LIBRARY (4th Issue 2006) and EMBASE (1966-2006) up to December 9, 2006, and analysed all publications included using a predefined evaluation sheet. Symptoms and severity of adverse events to coxibs were analysed based on all articles comprising such information. Subsequently, the probability for adverse events triggered by coxibs was determined on analyses of double-blind prospective trials only. Among 3,304 patients with NSAID intolerance, 119 adverse events occurred under coxib medication. All adverse events, except two, have been allergic/urticarial in nature; none was lethal, but two were graded as life-threatening (grade 4). The two non-allergic adverse events were described as a grade 1 upper respiratory tract haemorrhage, and a grade 1 gastrointestinal symptom, respectively. In 13
\end{abstract}

T. B. Weberschock · S.-M. Müller · W.-H. Boehncke $(\bowtie)$

Department of Dermatology,

Johann Wolfgang Goethe-University,

Theodor-Stern-Kai 7, 60590 Frankfurt am Main, Germany

e-mail: Boehncke@em.uni-frankfurt.de

S. Boehncke

Department of Internal Medicine,

Section for Endocrinology, Metabolism, and Diabetology,

Johann Wolfgang Goethe-University,

Frankfurt am Main, Germany double-blind prospective studies comprising a total of 591 patients with NSAID intolerance, only 13 adverse reactions to coxib provocations were observed. The triggering coxibs were rofecoxib (2/286), celecoxib (6/208), etoricoxib (4/ 56 ), and valdecoxib (1/41). This review documents the good tolerability of coxibs in patients with NSAID intolerance, for whom access to this class of drugs for short-term treatment of pain and inflammation is advantageous.

Keywords Non-steroidal anti-inflammatory drugs . Intolerance $\cdot$ Urticaria $\cdot$ Adverse drug reaction $\cdot$ Coxibs

\section{Introduction}

Non-steroidal anti-inflammatory drugs (NSAIDs) are the most commonly used therapeutics in the outpatient management of pain and inflammation in a wide spectrum of diseases. Their primary mode of action is the blockade of prostaglandin synthesis by cyclooxygenases (COX): Constitutively expressed COX-1 is involved in fundamental mechanisms of homeostasis, whereas the inducible COX-2 mediates inflammation. Therapeutic effects of NSAIDs are primarily related to their ability to inhibit COX-2, whereas some of their most frequent adverse effects may be caused by COX-1 inhibition (Fig. 1). In contrast to most "classic" NSAIDs which block both isoforms, the so-called coxibs preferentially inhibit COX-2. This may result in better tolerability, namely reduction of gastrointestinal side effects $[29,85]$.

Respiratory and cutaneous adverse events triggered by NSAIDs are among the most common drug-related intolerance reactions in medicine. Typically, these manifest as asthma attacks or urticaria. Pathogenesis of these symptoms seems to be related to COX-1 inhibition [76]. Therefore, 
Fig. 1 Cyclooxygenase isoforms. Non-steroidal antiinflammatory drugs (NSAIDs) block prostaglandin synthesis by cyclooxygenases $(C O X)$. Two isoforms exist of this enzyme: constitutively expressed COX-1 is involved in fundamental mechanisms of homeostasis, whereas the inducible isoform COX-2 mediates inflammation

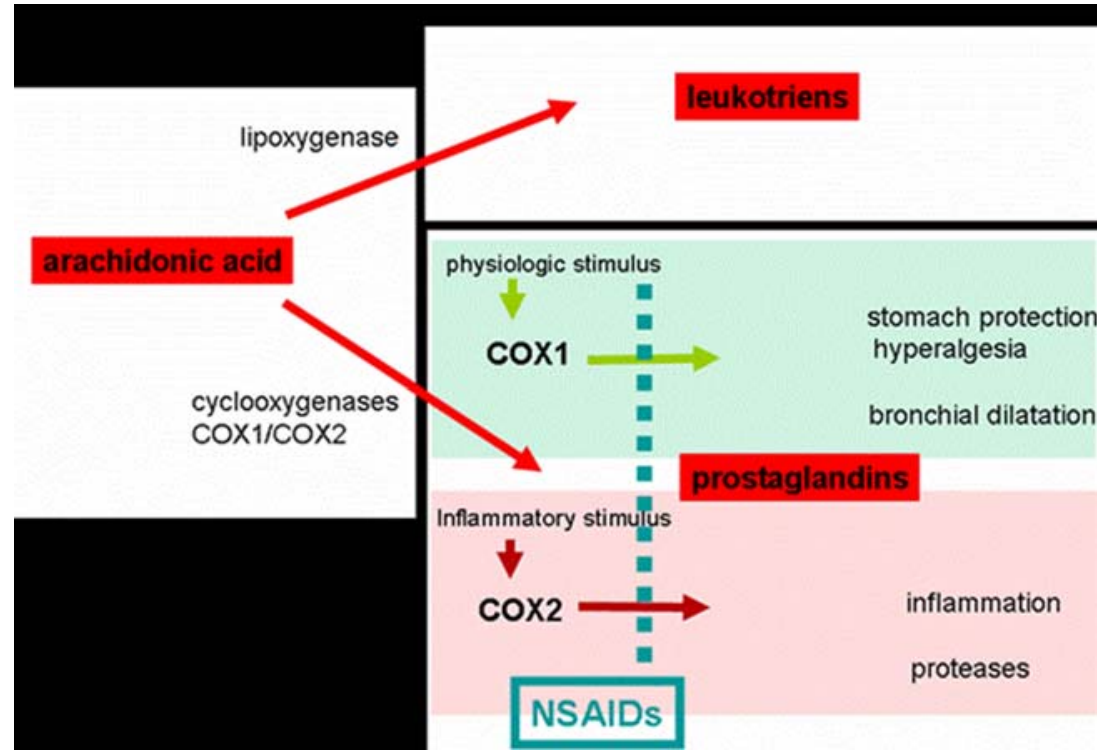

the hypothesis was put forward that coxibs may safely be used in patients with known NSAID intolerance. However, serious intolerance reactions to coxibs have also been observed, thus cautioning too euphoric expectations [71]. We therefore reviewed the relevant literature in a systematic and structured approach for evidence of coxib tolerance in patients with NSAID intolerance.

\section{Methods}

Search strategy

We searched MEDLINE (1966-2006), the COCHRANE LIBRARY (4th Issue 2006) and EMBASE (1966-2006) up to December 9, 2006. The following search terms were used: rofecoxib OR celecoxib OR valdecoxib OR parecoxib OR etoricoxib, combined with hypersensitivity OR intolerance. Those coxibs used in veterinary medicine (deracoxib, tiracoxib and cimicoxib) were not included in the literature search. No language or publication restriction was predefined. All publications reporting individual patients with NSAID intolerance and subsequent exposure to a COX-2 Inhibitor were identified and the reference lists of these articles were hand-searched for further publications. If articles could not be retrieved in full text, a copy was requested from the corresponding author and/or journal editor.

Inclusion criteria

Each publication was appraised for inclusion in a stepwise approach (Fig. 2). Only publications describing individual patients and providing a rational medication scheme as well as a sufficiently specific outcome report were included in this review. In a first step, evaluation focused on clinical symptoms and severity of adverse events in patients with NSAID intolerance. Therefore, all articles on this topic were included for this analysis. Subsequently, the probability for adverse events was analysed based exclusively on publications of double-blind prospective trials.

\section{Data extraction and synthesis}

All articles were analysed using a predefined evaluation sheet. Uncertainties were resolved by consensus decisions among the investigators. Data synthesis was qualitative and descriptive. The Common Terminology Criteria for Adverse Events version 3.0 (CTCAE) was used to categorize adverse events.

\section{Results}

We identified 230 publications on coxibs and/or NSAID intolerance. Hundred and forty-six references not focusing on individual patients with NSAID intolerance were excluded. Unclear medication schemes or outcome reports led to exclusion of two articles. Eighty-four publications were evaluated for severity and type of adverse reactions to coxibs. Thirteen publications on double-blind studies were used to determine the probability of adverse reactions to coxibs.

Severity and type of adverse events to coxibs

A total of 119 adverse events among 3,304 patients exposed to coxibs were identified [1-18, 20-24, 26-28, 30-35, 3758, 60-75, 77-84, 86-89]. Adverse events were described 
Fig. 2 Flow chart documenting the handling data (NSAID nonsteroidal anti-inflammatory drugs)

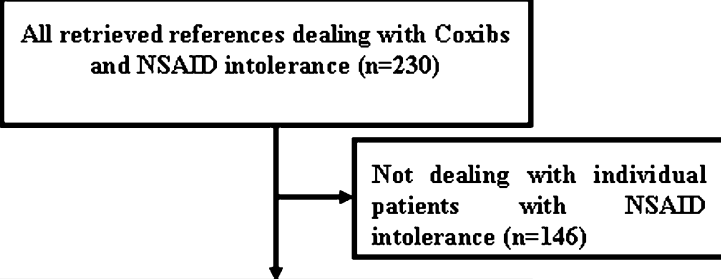
Articles dealing with individual patients
with NSAID intolerance $(\mathbf{n}=\mathbf{8 4})$

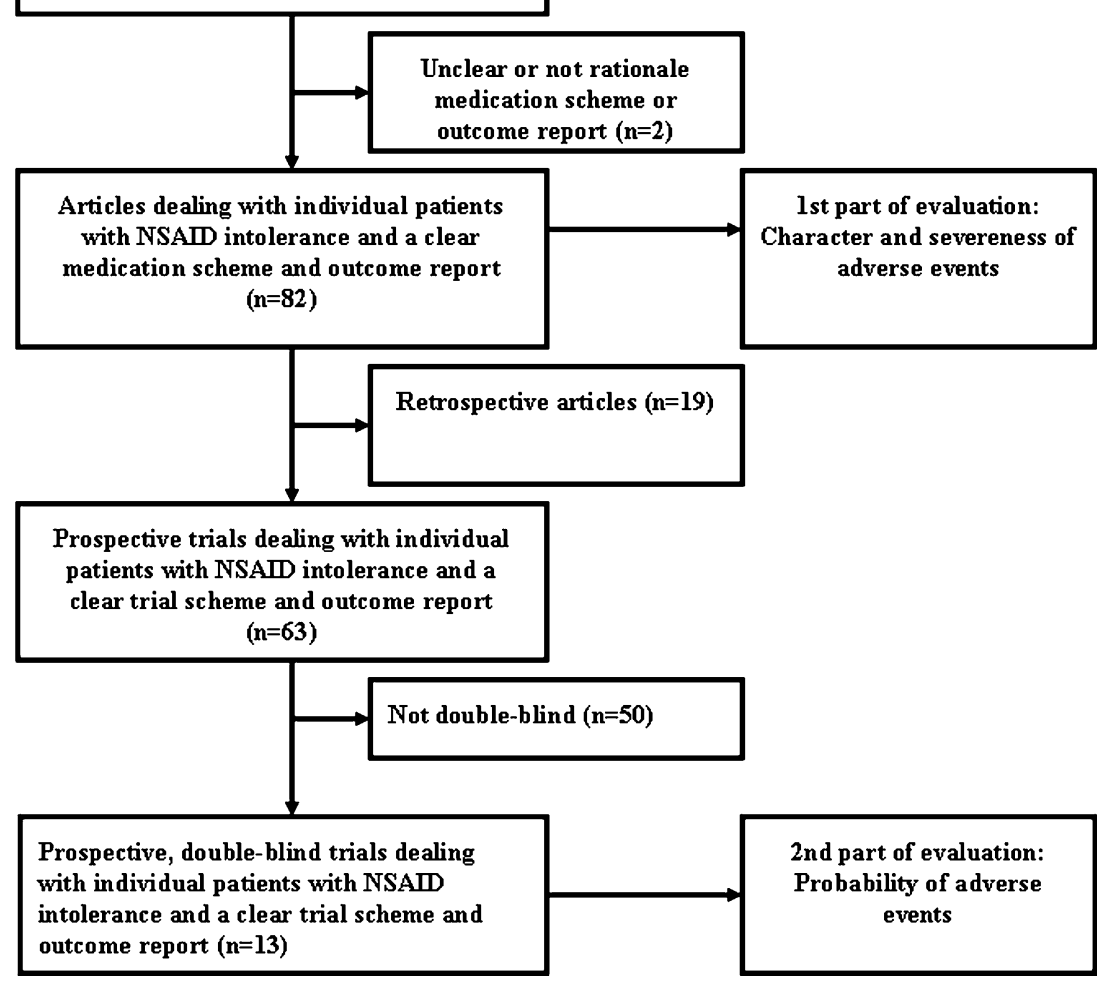

Table 1 Mode and severity of adverse event (CTCAE common terminology criteria for adverse events)

\begin{tabular}{|c|c|c|c|c|c|c|c|c|c|}
\hline & Patients & $\begin{array}{l}\text { Events } \\
\text { (total) }\end{array}$ & $\begin{array}{l}\text { Urticaria } \\
\text { (grade) }\end{array}$ & $\begin{array}{l}\text { Allergic } \\
\text { reactions } \\
\text { (grade) }\end{array}$ & $\begin{array}{l}\text { Allergic } \\
\text { rhinitis } \\
\text { (grade) }\end{array}$ & $\begin{array}{l}\text { Airway } \\
\text { obstruction } \\
\text { (grade) }\end{array}$ & $\begin{array}{l}\text { Gastroin-testinal } \\
\text { symtpms (grade) }\end{array}$ & $\begin{array}{l}\text { Pruritus } \\
\text { (grade) }\end{array}$ & $\begin{array}{l}\text { Hemorrhage, } \\
\text { upper respiratory } \\
\text { (grade) }\end{array}$ \\
\hline Rofecoxib & 1,732 & 48 & $\begin{array}{l}9(1) \\
8(2) \\
1(3)\end{array}$ & $\begin{array}{l}25(3) \\
1(4)\end{array}$ & $1(2)$ & $2(1)$ & 0 & 0 & $1(1)$ \\
\hline Celecoxib & 1,148 & 59 & $\begin{array}{l}19(1) \\
1(2)\end{array}$ & $\begin{array}{l}1(2) \\
33(3) \\
1(4)\end{array}$ & 0 & $1(1)$ & 0 & $3(2)$ & 0 \\
\hline Etoricoxib & 328 & 10 & $\begin{array}{l}3(1) \\
5(2)\end{array}$ & $1(3)$ & 0 & 0 & $1(1)$ & 0 & 0 \\
\hline Valdecoxib & 69 & 2 & $\begin{array}{l}1(1) \\
1(2)\end{array}$ & 0 & 0 & 0 & 0 & 0 & 0 \\
\hline Parecoxib & 27 & 0 & 0 & 0 & 0 & 0 & 0 & 0 & 0 \\
\hline Total & 3,304 & 119 & 48 & 62 & 1 & 3 & 1 & 3 & 1 \\
\hline
\end{tabular}

Numbers and grade of adverse events (in parentheses) are indicated

for rofecoxib (48/1,732), celecoxib $(59 / 1,148)$, etoricoxib (10/328), and valdecoxib (2/69), but not parecoxib $(0 / 27)$ (Table 1). All adverse events, except two, have been allergic/ urticarial in nature, and none was lethal. One adverse event after administration of rofecoxib and one after celecoxib were reported as life-threatening (grade 4). The two non- 


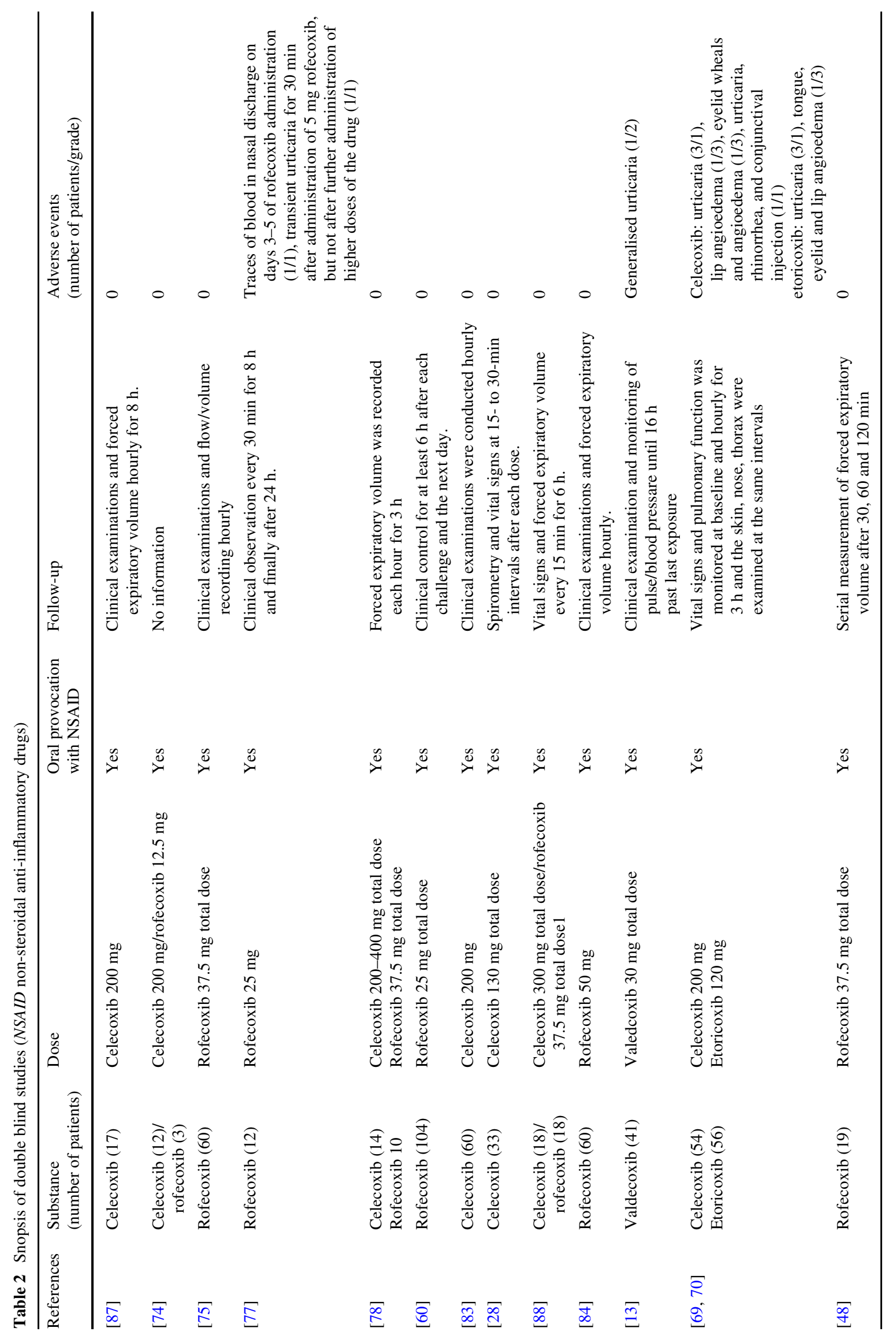


allergic adverse events were described as a grade 1 upper respiratory tract haemorrhage, namely blood in nasal discharge after provocation with rofecoxib, and a grade 1 gastrointestinal symptom, namely nausea and abdominal pain.

\section{Evaluation of double-blind studies}

We identified 13 double-blind studies evaluating tolerability of coxibs in a total of 591 NSAID intolerant patients (Table 2). The coxibs tested in the context of these studies were rofecoxib $(n=286)$, celecoxib $(n=208)$, etoricoxib $(n=56)$ and valdecoxib $(n=41)$. Among the 591 patients described, 13 exhibited adverse reactions upon provocation with a coxib. The triggering coxibs were rofecoxib (2/286), celecoxib (6/208), etoricoxib (4/56), and valdecoxib (1/41) $[13,28,48,60,69,74,75,77,78,83,84,87,88]$. One of these reactions was clearly non-allergic, this one being the above-mentioned individual with grade 1 upper respiratory tract haemorrhage.

\section{Discussion}

This systematic review documents the low probability of allergic/pseudo-allergic reactions induced by coxibs in patients with NSAID intolerance. To our knowledge, this is the first comprehensive analysis of data published on this topic. We have searched all three major medical databases available, namely MEDLINE, COCHRANE LIBRARY, and EMBASE using very broad and general search terms. Following identification of relevant publications, these were evaluated by means of a pre-defined evaluation form. The data available are described in the form of a structured review [19].

NSAIDs are among the most commonly prescribed therapeutics in the world. Although generally considered safe, their wide and frequent use results in these drugs being among the most common causes of drug-related intolerance reactions. This may at least in part be due to their nonselective inhibition of both cyclooxygenase isoforms. In line with this hypothesis, NSAIDs characterized by pronounced COX-1 inhibition bear a high risk to trigger asthma attacks in patients with aspirin-sensitive asthma bronchiale, whereas preferentially COX-2 inhibiting NSAIDS are better tolerated by these patients [36]. Our analysis of published studies on this issue further supports this notion, as only 13 of 591 NSAID-intolerant patients showed adverse reactions upon provocation with coxibs in double-blind clinical studies; all of these were grade 3 or milder. Still, relatively selective COX-2 inhibitors have been identified as triggers of serious intolerance reactions [71]. This implies that our current understanding of NSAID-triggered intolerance is still imperfect, and its path- ogenesis cannot be reduced to cyclooxygenase-mediated effects alone, but needs to take into account clinically relevant additional NSAID-mediated effects such as secretion of leukotrienes from mast cells and other leukocytes.

It has been suggested that coxibs may confer an elevated risk for acute myocardial infarction and sudden cardiac death, namely after long-term therapy [25]. As a reaction, several coxibs are no longer available despite a recommendation by the participants of an expert meeting organized by the Food and Drug Administration to grant further prescription of rofecoxib, celecoxib and valdecoxib in the US [59]. On the other hand, substantial evidence described here points towards a good tolerability of coxibs in patients with NSAID intolerance. Given the wide use of NSAIDs in the short-term treatment of trivial signs and symptoms, the availability of coxibs for these indications would be advantageous for this relevant subpopulation of patients, since this type of application is unlikely to increase cardiac risk.

\section{References}

1. Ahlbach S, Usadel KH, Kaufmann R, Boehncke WH (2003) The selective cyclooxygenase- 2 inhibitor celecoxib is a safe alternative in patients with pseudo-allergic reactions to nonsteroidal antiinflammatory drugs. Med Klin (Munich) 98:242-244

2. Andri L (2001) Safety of celecoxib in patients with ASA/NSAIDs sensitivity (abstract). Allergy 56:223

3. Asero R (2001) Tolerability of rofecoxib. Allergy Eur J Allergy Clin Immunol 56:916-917

4. Asero R (2003) Chronic urticaria with multiple NSAID intolerance: Is tramadol always a safe alternative analgesic? J Investig Allergol Clin Immunol 13:56-59

5. Asero R (2005) Oral aspirin challenges in patients with a history of intolerance to single non-steroidal anti-inflammatory drugs. Clin Exp Allergy 35:713-716

6. Asero R (2006) Use of ketoprofen oral challenges to detect crossreactors among patients with a history of aspirin-induced urticaria. Ann Allergy Asthma Immunol 97:187-189

7. Asero R, Tedeschi A, Lorini M (2002) Autoreactivity is highly prevalent in patients with multiple intolerances to NSAIDs. Ann Allergy Asthma Immunol 88:468-472

8. Baldassarre S, Schandene L, Choufani G, Michils A (2006) Asthma attacks induced by low doses of celecoxib, aspirin, and acetaminophen. J Allergy Clin Immunol 117:215-217

9. Bavbek S, Celik G, Ozer F, Mungan D, Misirligil Z (2004) Safety of selective COX-2 inhibitors in aspirin/nonsteroidal anti-inflammatory drug-intolerant patients: comparison of nimesulide, meloxicam, and rofecoxib. J Asthma 41:67-75

10. Bavbek S, Celik G, Pasaoglu G, Misirligil Z (2006) Rofecoxib, as a safe alternative for acetyl salicylic acid/nonsteroidal anti-inflammatory drug-intolerant patients. J Investig Allergol Clin Immunol $16: 57-62$

11. Berges-Gimeno MP, Camacho-Garrido E, Garcia-Rodriguez RM, Alfaya T, Martin Garcia C, Hinojosa M (2001) Rofecoxib safe in NSAID hypersensitivity. Allergy Eur J Allergy Clin Immunol 56:1017-1018

12. Bochenek G, Nizankowska E, Mejza F, Sierczynska M, Szczeklik A (2001) Good tolerance of rofecoxib in aspirin-induced asthma. Eur Respir J 18:424s 
13. Boehncke S, Boehncke WH (2005) Tolerance to coxibs in patients with intolerance to non-steroidal anti-inflammatory drugs (NSAIDs). Dtsch Med Wochenschr 130:2249-2252

14. Carretero P, Perez R, Garces MM (2007) Tolerance to Celecovix in patients with NSAID intolerance (abstract). Allergy 56:222

15. Celik G, Erkekol FO, Bavbek S, Dursun B, Misirligil Z (2005) Long-term use and tolerability of cyclooxygenase- 2 inhibitors in patients with analgesic intolerance. Ann Allergy Asthma Immunol 95:33-37

16. Celik G, Pasaoglu G, Bavbek S, Abadoglu O, Dursun B, Mungan D et al (2005) Tolerability of selective cyclooxygenase inhibitor, celecoxib, in patients with analgesic intolerance. J Asthma 42:127-131

17. Dahlen B, Szczeklik A, Murray JJ (2001) Celecoxib in patients with asthma and aspirin intolerance. The Celecoxib in AspirinIntolerant Asthma Study Group. N Engl J Med 344:S142

18. Dama AR, Lobefalo G, Bonadona P, Schiappoli M, Crivellaro M (2002) Celecoxib, a new selective COX-2 Inhibitor is a safe alternative drug in NSAID-intolerant patients (abstract). J Allergy Clin Immunol S141

19. Egger M, Smith GD, Sterne JA (2001) Uses and abuses of metaanalysis. Clin Med 1:478-484

20. El Miedany Y, Youssef S, Ahmed I, El Gaafary M (2006) Safety of etoricoxib, a specific cyclooxygenase-2 inhibitor, in asthmatic patients with aspirin-exacerbated respiratory disease. Ann Allergy Asthma Immunol 97:105-109

21. Enrique E, Cistero-Bahima A, Miguel-Moncin MM, Alonso R (2000) Rofecoxib should be tried in NSAID hypersensitivity. Allergy 55:1090

22. Fernandez-Melendez S, Miranda A, Carmona MJ, Diaz J, Barcelo JM, Vega JM et al (2002) Tolerance of rofecoxib in patients with adverse reactions to nonsteroidal ant-inflammatory drugs (NSAIDs). J Allergy Clin Immunol 109:S140

23. Garcia-Rodriguez RM, Hinojosa M, Camacho-Garrido E, Berges GP, Martin GC (2002) Celecoxib, safe in NSAID intolerance. Allergy 57:1085-1086

24. Giamarchi D, Escamilla R, Carme S, Krempf M (2004) Selective COX-2 inhibitors: a safety alternative for patients with intolerance to non-steroidal anti-inflammatory drugs (NSAIDs) (abstract). J Allergy Clin Immunol 113:S180

25. Graham DJ, Campen D, Hui R, Spence M, Cheetham C, Levy G et al (2005) Risk of acute myocardial infarction and sudden cardiac death in patients treated with cyclo-oxygenase 2 selective and non-selective non-steroidal anti-inflammatory drugs: nested casecontrol study. Lancet 365:475-481

26. Grimm V, Rakoski J, Ring J (2002) Urticaria and angioedema induced by COX-2 inhibitors. J Allergy Clin Immunol 109:370

27. Grob M, Pichler WJ, Wuthrich B (2002) Anaphylaxis to celecoxib. Allergy 57:264-265

28. Gyllfors P, Bochenek G, Overholt J, Drupka D, Kumlin M, Sheller $\mathrm{J}$ et al (2003) Biochemical and clinical evidence that aspirin-intolerant asthmatic subjects tolerate the cyclooxygenase 2-selective analgetic drug celecoxib. J Allergy Clin Immunol 111:1116-1121

29. Hawkey CJ (1999) COX-2 inhibitors. Lancet 353:307-314

30. Hinrichs R, Ritzkowsky A, Hunzelmann N, Krieg T, ScharffetterKochanek K (2001) Rofecoxib as an alternative in aspirin hypersensitivity. Allergy 56:789

31. Hinrichs R, Ritzkowsky A, Hunzelmann N, Scharffetter-Kochanek $\mathrm{K}$ (2001) Cox-2 inhibitors - An alternative in analgesic intolerance. H G Z Hautkr 76:126-127

32. Kalyoncu AF, Karakaya G, Bozkurt B, Artvinli M (2005) A new method of oral drug provocation testing for determining safe alternatives for patients with non-steroidal anti-inflammatory drug intolerance: the triple test. Int Arch Allergy Immunol 138:319-323

33. Karakaya G, Kalyoncu AF (2000) Safety of nimesulide, meloxicam and rofecoxib as alternative analgesics. Allergol Immunopathol (Madr) 28:319-321
34. Kelkar PS, Butterfield JH, Teaford HG (2001) Urticaria and angioedema from cyclooxygenase- 2 inhibitors. J Rheumatol 28:2553-2554

35. Kleinhans M, Linzbach L, Zedlitz S, Kaufmann R, Boehncke W$\mathrm{H}$ (2002) Positive patch test reactions to celecoxib may be due to irritation and do not correlate with the results of oral provocation. Contact Dermatitis 47:100-102

36. Kosnik M, Music E, Matjaz F, Suskovic S (1998) Relative safety of meloxicam in NSAID-intolerant patients. Allergy 53:1231-1233

37. Kruse R, Ruzicka T, Grewe M (2003) Intolerance reactions due to the selective cyclooxygenase type II inhibitors rofecoxib and celecoxib: results of oral provocation tests in patients with NSAID hypersensitivity. Acta Derm Venereol 83:183-185

38. Leong KP, Tang CY, Thong B (2002) The safety of rofecoxib in patients with NSAID-induced urticaria and angioedema. J Allergy Clin Immunol 109:S140

39. Levy MB, Fink JN (2001) Anaphylaxis to celecoxib. Ann Allergy Asthma Immunol 87:72-73

40. Liccardi G, Cazzola M, De Giglio C, Manfredi D, Piscitelli E, D'Amato M et al (2005) Safety of celecoxib in patients with adverse skin reactions to acetaminophen (paracetamol) and other non-steroidal anti-inflammatory drugs. J Investig Allergol Clin Immunol 15:249-253

41. Liccardi G, D'Amato G, Canonica GW, Lobefalo G, Noschese P, Piccolo A et al (2005) Safety of celecoxib in patients with adverse reactions to nimesulide. Allergy 60:708-709

42. Marks F, Harrell K, Fischer R (2001) Successful use of cyclooxygenase- 2 inhibitor in a patient with aspirin-induced asthma. South Med J 94:256-257

43. Marshall LL (2005) Angioedema associated with aspirin and rofecoxib. Ann Pharmacother 39:944-948

44. Martin GC, Hinojosa M, Berges P, Camacho E, Garcia RR, Alfaya $\mathrm{T}$ et al (2002) Safety of a cyclooxygenase-2 inhibitor in patients with aspirin-sensitive asthma. Chest 121:1812-1817

45. Martin-Garcia C, Hinojosa M, Berges P, Camacho E, GarciaRodriguez R, Alfaya T (2003) Celecoxib, a highly selective COX2 inhibitor, is safe in aspirin-induced asthma patients. J Investig Allergol Clin Immunol 13:20-25

46. Mastalerz L, Sanak M, Gawlewicz A, Gielicz A, Faber J, Szczeklik A (2006) Different eicosanoid profile of the hypersensitivity reactions triggered by aspirin and celecoxib in a patient with sinusitis, asthma, and urticaria. J Allergy Clin Immunol 118:957-958

47. Matucci A, Parronchi P, Vultaggio A, Rossi O, Brugnolo F, Maggi E et al (2004) Partial safety of the new COX-2 inhibitor rofecoxib in NSAIDs high sensitive patients. Allergy 59:1133-1134

48. Micheletto C, Tognella S, Guerriero M, Dal Negro R (2006) Nasal and bronchial tolerability of Rofecoxib in patients with aspirin induced asthma. Allerg Immunol (Paris) 38:10-14

49. Montalvo S, Davila I, Laffond E, Moreno E, Lorente F (2003) Rofecoxib tolerance in patients with NSAID-induced reactions. Alergol Inmunol Clin 18:214-216

50. Morais-Almeida M, Marinho S, Rosa S, Gaspar A, Rosado-Pinto JE (2006) Multiple drug intolerance including etoricoxib. Allergy 61:144-145

51. Munoz-Bellido FJ, Terron M, Leon A (2003) Safety of rofecoxib in nonsteroidal anti-inflammatory drugs intolerance. Allergy 58:1072-1075

52. Muratore L, Calogiuri GF, Calcagnile F, Quarta E, Muratore M, Ventura MT et al (2005) Tolerability of etoricoxib in patients affected by non steroidal anti-inflammatory drugs induced urticaria: a single blind placebo study on 37 subjects. Ital J Allergy Clin Immunol 15:73-79

53. Nahar IK, Muqim AT, Al Qhouti BI, Al Herz AA, Shehab DK, Uppal SS et al (2006) The use of etoricoxib in patients with bronchial asthma associated with aspirin sensitivity. Saudi Med J 27:119-120 
54. Nekzai E, Hunzelmann N (2002) Intolerance reaction to the cyclooxygenase- 2 inhibitor rofecoxib in a patient with analgesic intolerance. H G Z Hautkr 77:246-247

55. Nettis E, Colanardi MC, Ferrannini A, Tursi A (2005) Short-term and long-term tolerability of rofecoxib in patients with prior reactions to nonsteroidal anti-inflammatory drugs. Ann Allergy Asthma Immunol 94:29-33

56. Nettis E, Colanardi MC, Ferrannini A, Vacca A, Tursi A (2005) Short-term tolerability of etoricoxib in patients with cutaneous hypersensitivity reactions to nonsteroidal anti-inflammatory drugs. Ann Allergy Asthma Immunol 95:438-442

57. Nifosi G (2002) COX-2 inhibitors in allergy. Gazz Med Ital Arch Sci Med 161:109-111

58. Novotna B, Lanikova Z, Dolina J (2002) Tolerance to rofecoxib in patients with aspirin-sensitivity. Alergie 4:149-151

59. Okie S (2005) Raising the safety bar-the FDA's coxib meeting. N Engl J Med 352:1283-1285

60. Pacor ML, Di Lorenzo G, Biasi D, Barbagallo M, Corrocher R (2002) Safety of rofecoxib in subjects with a history of adverse cutaneous reactions to aspirin and/or non-steroidal anti-inflammatory drugs. Clin Exp Allergy 32:397-400

61. Passero M, Chowdhry S, Hinojosa M, Martin-Garcia C (2003) Cyclooxygenase-2 inhibitors in aspirin-sensitive asthma [2]. Chest 123:2155-2156

62. Perrone MR, Artesani MC, Viola M, Gaeta F, Caringi M, Quaratino D et al (2003) Tolerability of rofecoxib in patients with adverse reactions to nonsteroidal anti-inflammatory drugs: a study of 216 patients and literature review. Int Arch Allergy Immunol 132:82-86

63. Quiralte J, Delgado J, Saenz de San PB, Lopez-Pascual E, Nieto MA, Ortega N et al (2004) Safety of the new selective cyclooxygenase type 2 inhibitors rofecoxib and celecoxib in patients with anaphylactoid reactions to nonsteroidal anti-inflammatory drugs. Ann Allergy Asthma Immunol 93:360-364

64. Quiralte J, Saenz de San PB, Florido JJ (2002) Safety of selective cyclooxygenase-2 inhibitor rofecoxib in patients with NSAID-induced cutaneous reactions. Ann Allergy Asthma Immunol 89:63-66

65. Rodriguez M, Enrique E, Castello JV, De Mateo JA, Roca B, Malek T (2003) Tolerability of cyclooxygenase 2 inhibitors and the advisability of oral challenge [3]. Ann Allergy Asthma Immunol 91:589

66. Roll A, Wuethrich B, Schmid-Grendelmeier P, Hofbauer G, Ballmer-Weber B (2006) Tolerance to celecoxib in patients with a history of adverse reactions to nonsteroidal anti-inflammatory drugs. Swiss Med Wkly 136:684-690

67. Sanchez BM, Capriles-Hulett A, Caballero-Fonseca F, Perez CR (2001) Tolerability to new COX-2 inhibitors in NSAID-sensitive patients with cutaneous reactions. Ann Allergy Asthma Immunol 87:201-204

68. Sanchez-Borges M, Capriles-Hulett A, Caballero-Fonseca F (2001) NSAID hypersensitivity in the COX-2 inhibitor era. Allergy Clin Immunol Int J World Allergy Org 211-218

69. Sanchez-Borges M, Caballero-Fonseca F, Capriles-Hulett A (2005) Safety of etoricoxib, a new cyclooxygenase 2 inhibitor, in patients with nonsteroidal anti-inflammatory drug-induced urticaria and angioedema. Ann Allergy Asthma Immunol 95:154-158

70. Sanchez-Borges M, Caballero-Fonseca F, Capriles-Hulett A (2005) Tolerance of nonsteroidal anti-inflammatory drug-sensitive patients to the highly specific cyclooxygenase 2 inhibitors rofecoxib and valdecoxib. Ann Allergy Asthma Immunol 94:34-38

71. Schellenberg RR, Isserow SH (2001) Anaphylactoid reaction to a cyclooxygenase- 2 inhibitor in a patient who had a reaction to a cyclooxygenase-1 inhibitor. N Engl J Med 345:1856
72. Schubert B, Grosse Perdekamp MT, Pfeuffer P, Raith P, Brocker E-B, Trautmann A (2005) Nonsteroidal anti-inflammatory drug hypersensitivity: fable or reality? Eur J Dermatol 15:164-167

73. Senna G, Bilo MB, Antonicelli L, Schiappoli M, Crivellaro MA, Bonadonna P et al (2004) Tolerability of three selective cyclo-oxygenase-2 inhibitors, meloxicam, celecoxib and rofecoxib in NSAID-sensitive patients. Allerg Immunol (Paris) 36:215-218

74. Stevenson DD, Simon RA, Christiansen SC (2000) Lack of crossreactivity between selective COX-2 inhibitors and aspirin (ASA) in ASA-sensitive asthmatics (abstract). J Allerg Clin Immunol S273

75. Stevenson DD, Simon RA (2001) Lack of cross-reactivity between rofecoxib and aspirin in aspirin-sensitive patients with asthma. J Allergy Clin Immunol 108:47-51

76. Stevenson DD, Zuraw BL (2003) Pathogenesis of aspirin-exacerbated respiratory disease. Clin Rev Allergy Immunol 24:169188

77. Szczeklik A, Nizankowska E, Bochenek G, Nagraba K, Mejza F, Swierczynska M (2001) Safety of a specific COX-2 inhibitor in aspirin-induced asthma. Clin Exp Allergy 31:219-225

78. Vaghi A, De Bernardi G, Grassi N, Capato S, Cicchitto G, Sestini $P$ et al (2001) Tolerance of two cox2inhibitors, rofecoxib and celecoxib, in aspirin sensitive asthmatics. Eur Respir J 18:428s

79. Valero A, Baltasar M, Enrique E, Pau L, Dordal MT, Cistero A et al (2002) NSAID-sensitive patients tolerate rofecoxib. Allergy 57:1214-1215

80. Valero A, Enrique E, Baltasar M, Cistero A, Marti E, Picado C (2003) Celecoxib in NSAID-induced cutaneous and respiratory adverse reactions. Med Clin (Barc) 121:695-696

81. Viola M, Quaratino D, Gaeta F, Caringi M, Valluzzi R, Caruso C et al (2005) Celecoxib tolerability in patients with hypersensitivity (mainly cutaneous reactions) to nonsteroidal anti-inflammatory drugs. Int Arch Allergy Immunol 137:145-150

82. Viola M, Quaratino D, Volpetti S, Gaeta F, Romano A (2006) Parecoxib tolerability in patients with hypersensitivity to nonsteroidal anti-inflammatory drugs. J Allergy Clin Immunol 117:1189-1191

83. Woessner KM, Simon RA, Stevenson DD (2002) The safety of celecoxib in patients with aspirin-sensitive asthma. Arthritis Rheum 46:2201-2206

84. Woessner KM, Simon RA, Stevenson DD (2004) Safety of highdose rofecoxib in patients with aspirin-exacerbated respiratory disease. Ann Allergy Asthma Immunol 93:339-344

85. Wolfe MM, Lichtenstein DR, Singh G (1999) Gastrointestinal toxicity of nonsteroidal antiinflammatory drugs. N Engl J Med 340:1888-1899

86. Wyplosz B, Vautier S, Lillo-Le Louet A, Capron L (2006) Tolerance of diclofenac after hypersensitivity to celecoxib and to nabumetone. Br J Clin Pharmacol 61:474

87. Yoshida S, Ishizaki Y, Onuma K, Shoji T, Nakagawa H, Amayasu H (2000) Selective cyclo-oxygenase 2 inhibitor in patients with aspirin-induced asthma [2]. J Allergy Clin Immunol 106:12011202

88. Zembowicz A, Mastalerz L, Setkowicz M, Radziszewski W, Szczeklik A (2003) Safety of cyclooxygenase 2 inhibitors and increased leukotriene synthesis in chronic idiopathic urticaria with sensitivity to nonsteroidal anti-inflammatory drugs. Arch Dermatol 139:1577-1582

89. Zollner TM, Ahlbach S, Kaufmann R, Boehncke WH (2001) Tolerability of a selective cyclooxygenase-2-inhibitor (rofecoxib) in patients with intolerance reactions to nonsteroidal anti-inflammatory agents. Dtsch Med Wochenschr 126:386-388 